Journal of Mathematics and Statistics 7 (1): 57-60, 2011

ISSN 1549-3644

(C) 2010 Science Publications

\title{
Analysis of a Two Unit Standby Oil Delivering System with a Provision of Switching Over to another System at Need to Increase the Availability
}

\author{
${ }^{1}$ Upasana Sharma, ${ }^{1}$ Rekha and ${ }^{2}$ Gulshan Taneja \\ ${ }^{1}$ Department of Statistics, Punjabi University, Patiala \\ ${ }^{2}$ Department of Mathematics, Maharishi Dayanand University, Rohtak, Haryana, India
}

\begin{abstract}
Problem statement: The study deals with a standby system consisting of two units. Initially one unit is operative and the other is standby. When both the units are failed then there is a provision of switching over to the other similar system. This practical situation may be observed in an oil refinery plant. Real data on failure and repair rates of such units collected from oil refinery plant, Pani pat, India have been used for present study. Approach: The system is analyzed by making use of semi-Markov processes and regenerative point technique. Results: Expression for the expected profit is obtained after obtaining various measures of system effectiveness. Graphical analysis is also done for a particular case and various interpretations are made. Conclusion: Upper/lower limits for various rates/costs/probabilities can be obtained to get the positive profit for the system and to decide about the least value of the price of the product to be produced.
\end{abstract}

Key words: Oil delivering standby system, Semi Markov process, regenerative point technique, measures of system effectiveness, profit analysis

\section{INTRODUCTION}

Two-unit standby systems have been discussed by various researchers including (Tuteja et al., 2001a; 2001b; Goyal et al., 2009; Gopalan and Nagarwall, 1985; Tuteja and Taneja, 1992; Khaled and Mohammed, 2005) in the field of reliability under various assumptions/considerations. Most of these studies are not based on the real data. However, some researchers including (Taneja et al., 2007; Parasher and Taneja, 2007) studied some reliability models collecting real data on failure and repair rates of the units used in such systems. But none of the researchers considered the concept of another line facility which has been used in the present paper. Practical example of such a system is an oil delivering system which can be seen in an oil refinery plant wherein on the failure of one standby oil delivering system, the supply is done by switching over to another system .This is done by changing a valve. A valve is a device which is used for switching over to another system. The present study is based on the data collected on the failure and repair rates for the oil delivering system working in the Oil Refinery Plant, Panipat, India. It was observed that the main unit may fail due to some repairable faults or some irreparable fault in some component(s) which, therefore, are replaced.
Initially one unit is operative and the other is standby. On the failure of the operative unit, it is repaired or its component is replaced with a new one according as it is repairable or irreparable. The standby unit becomes operative at this stage. On the failure of both the units, we switch over to the other system to avoid down time as the company may have other line facilities. Failure time is assumed to have exponential distribution. Repair/Replacement times have been taken as arbitrary.

\section{MATERIALS AND METHODS}

In this study, the probabilistic analysis of the system is analyzed by making use of semi-Markov processes and regenerative point technique and have obtained various measures of system effectiveness such as Mean time to system failure, Availability , busy period analysis of repairman for repair and replacement. and profit function

\section{Notations: $\lambda$ $\alpha_{1}$ $\alpha_{2}$ $\mathrm{p} \quad$ prob. That unit is under repair $\mathrm{q} \quad$ prob. that unit is under replacement}




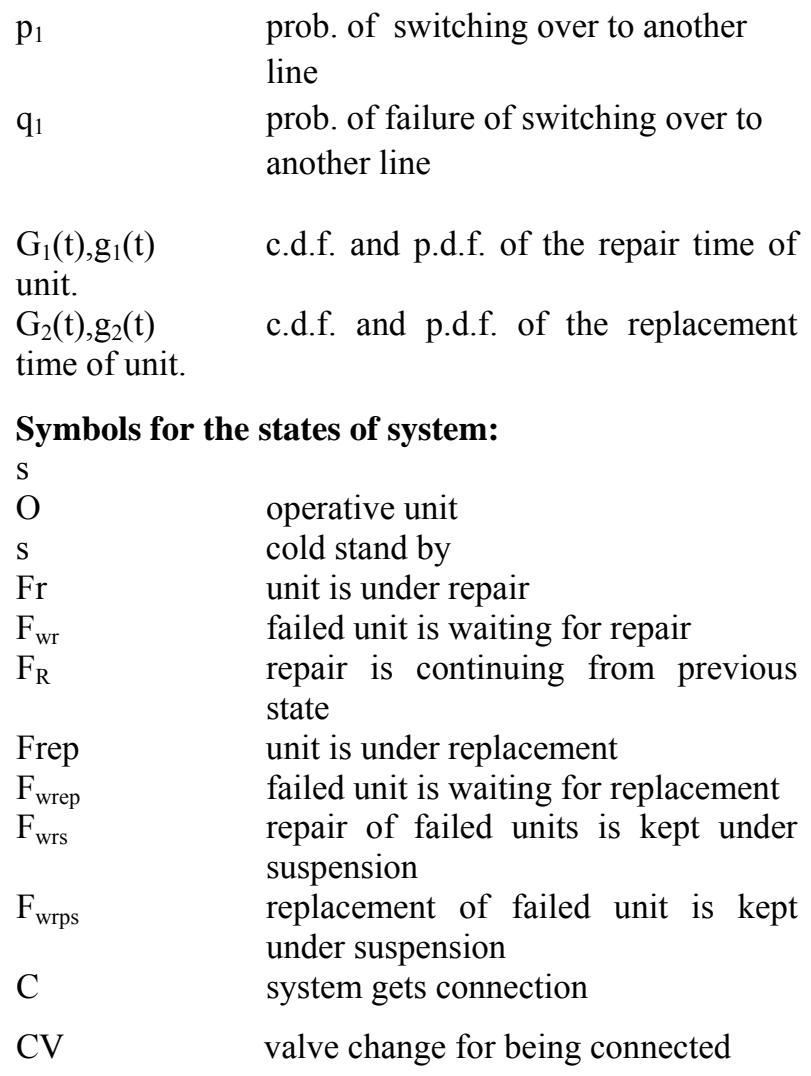

\section{RESULTS AND DISCUSSION}

The following particular case is considered for Results:

$$
\mathrm{g}_{1}(\mathrm{t})=\alpha_{1} \mathrm{e}^{\alpha_{1}(\mathrm{t})}, \mathrm{g}_{2}(\mathrm{t})=\alpha_{2} \mathrm{e}^{\alpha_{21}(\mathrm{t})}
$$

Various estimated values on the basis of collected data are:

$$
\lambda=0.0001397, \alpha_{1}=0.01736, \alpha_{2}=0.0123
$$

By taking the values of $\beta=20 \mathrm{p}_{1}=.8, \mathrm{p}=.82, \mathrm{C}_{2}$ $=10000, \mathrm{C}_{3}=2000, \mathrm{C}_{4}=79475, \mathrm{C}_{5}=5000$, the graph for profit with respect to cost per unit up revenue $\left(\mathrm{C}_{0}\right)$ for different values of cost per visit $\left(\mathrm{C}_{1}\right)$ of repairman.

Transition probabilities and mean sojourn times: A transition diagram showing the various states of the system is shown in Fig. 1. The epochs of entry into states $0,1,2,4,5,8$ and 10-14 are regeneration points and hence these are regenerative states. States 3-10 are failed states. The non-zero elements $p_{i j}$ are given below:

$$
\begin{aligned}
& \mathrm{p}_{01}=\mathrm{p} \\
& \mathrm{p}_{02}=\mathrm{q} \\
& \mathrm{P}_{10}=\mathrm{g}_{1}{ }^{*}(\lambda)
\end{aligned}
$$

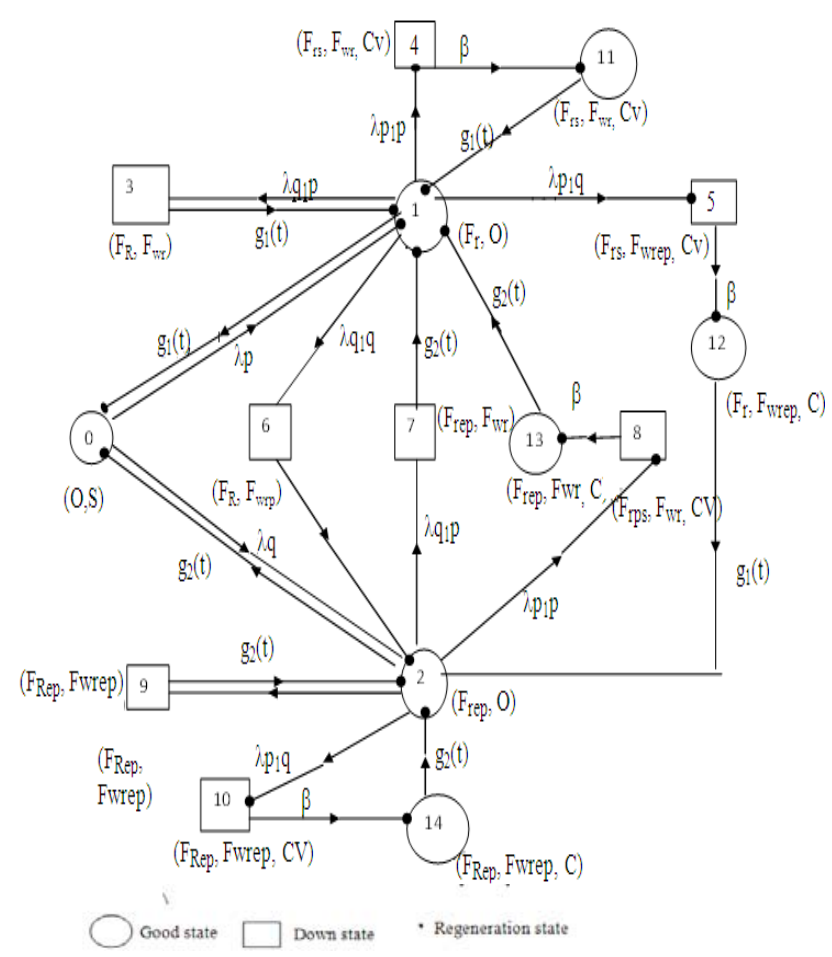

Fig. 1: State Transition Diagram

$$
\begin{aligned}
& \mathrm{p}_{13}=\mathrm{q}_{1} \mathrm{p}\left\{1-\mathrm{g}_{1}{ }^{*}(\lambda)\right\} \\
& \mathrm{p}_{14}=\mathrm{pp}_{1}\left\{1-\mathrm{g}_{1}{ }^{*}(\lambda)\right\} \\
& \mathrm{p}_{15}=\mathrm{p}_{1} \mathrm{q}\left\{1-\mathrm{g}_{1}{ }^{*}(\lambda)\right\} \\
& \mathrm{p}_{16}=\mathrm{q}_{1} \mathrm{q}\left\{1-\mathrm{g}_{1}{ }^{*}(\lambda)\right\} \\
& \mathrm{p}_{20}=\mathrm{g}_{2}{ }^{*}(\lambda) \\
& \mathrm{p}_{27}=\mathrm{q}_{1} \mathrm{p}\left\{1-\mathrm{g}_{2}{ }^{*}(\lambda)\right\} \\
& \mathrm{p}_{28}=\mathrm{p}_{1} \mathrm{p}\left\{1-\mathrm{g}_{2}{ }^{*}(\lambda)\right\}
\end{aligned}
$$

The mean sojourn time $\left(\mu_{\mathrm{i}}\right)$ in the regenerative state ' $\mathrm{i}$ ' is given by:

$$
\begin{gathered}
\mu_{0}=\frac{1}{\lambda} \mu_{1}=\frac{1-\mathrm{g}_{1}^{*}(\lambda)}{\lambda} \\
\mu_{2}=\frac{1-\mathrm{g}_{2}{ }^{*}(\lambda)}{\lambda} \\
\mu_{4}=\frac{1}{\beta}=\mu_{5} \\
\mu_{11}=\mathrm{g}_{1}{ }^{*}(0)=\mu_{12} \\
\mu_{13} \mathrm{~g}_{2}{ }^{* \prime}(0)=\mu_{1}
\end{gathered}
$$

The unconditional mean time taken by the system to transit for any regenerative state ' $j$ ' when it (time) is counted from the epoch of entrance in to state ' $\mathrm{i}$ ' is mathematically stated as: 


$$
\mathrm{m}_{\mathrm{ij}}=\int_{0}^{\infty} \mathrm{t} \mathrm{dQ}_{\mathrm{ij}}(\mathrm{t})=-\mathrm{tq}_{\mathrm{ij}} *^{\prime}(0)
$$

Thus:

$$
\begin{aligned}
& \mathrm{m}_{01}+\mathrm{m}_{02}=\mu_{0} \\
& \mathrm{~m}_{10}+\mathrm{m}_{13}+\mathrm{m}_{14}+\mathrm{m}_{15}+\mathrm{m}_{16}=\mu_{1} \\
& \mathrm{~m}_{20}+\mathrm{m}_{27}+\mathrm{m}_{28}+\mathrm{m}_{29}+\mathrm{m}_{2,10}=\mu \\
& \mathrm{m}_{5,12}=\mathrm{m}_{8,13}=\mathrm{m}_{10,14}=\mu_{4}=\mu_{8}=\mu_{10}
\end{aligned}
$$

Figure 2 depicts shows the behavior of Profit(P) with respect to cost per unit up revenue $\left(\mathrm{C}_{0}\right)$ for different values of cost per visit $\left(\mathrm{C}_{1}\right)$ of repairman. It can be interpreted that profit increases with increased in the value of revenue per unit up time $\left(\mathrm{C}_{0}\right)$ and has values of cost per visit $\left(\mathrm{C}_{1}\right)$ of the repairman. It can also be noticed if $\mathrm{C}_{1}=100$, then $\mathrm{p}>$ or $=$ or $<0$ according as $\mathrm{C}_{0}>$ or $=$ or $<32.37$. So for $\mathrm{C}_{1}=100$, the revenue per unit up time should be $>32.37$. Similarly for $C_{1}=20000$ and 50,000 the values of revenue per unit up time should not be less than 35.11 and 38.67 respectively.

Measures of the system effectiveness: Various measures of the system effectiveness obtained in steady state using the arguments of the theory of regenerative process are as under:

The Mean Time to System Failure (MTSF)

The availability of the system $\left(\mathrm{A}_{0}\right)$

$=\mathrm{N} / \mathrm{D}$

Busy period analysis of repair time only $\left(\mathrm{B}_{0}\right)$

$=\mathrm{N}_{1} / \mathrm{D}_{1}$

Busy period analysis of replacement time only $\left(\mathrm{BR}_{0}\right)=\mathrm{N}_{3} / \mathrm{D}_{1}$

Expected no of visits by repairman $\left(\mathrm{V}_{0}\right)=\mathrm{N}_{4} / \mathrm{D}_{1}$

Expected no of replacements $\quad=\mathrm{N}_{5} / \mathrm{D}_{1}$

Expected time during which the operation

is performed by some other system on

the failure of both the units $\left(\mathrm{AP}_{0}\right) \quad=\mathrm{N}_{6} / \mathrm{D}_{1}$

Where:

$\mathrm{N}=1+\mu_{0} \quad \mathrm{p}_{34}+\mu_{2}\left(1-\mathrm{p}_{35}\right)+\mu_{1}\left(\mathrm{p}_{34} \quad \mathrm{p}_{01}\right)+\mu_{4}\left(\mathrm{p}_{34} \quad \mathrm{p}_{01}\right)+\mu_{5}$ $\mathrm{p}_{35}+\mu_{3}$

$\mathrm{D}=\tilde{1} \mathrm{p}_{35} \mathrm{p}_{53}-\mathrm{p}_{23} \mathrm{p}_{34}\left(\mathrm{p}_{40} \mathrm{p}_{01} \mathrm{p}_{12}+\mathrm{p}_{02}\right)$

$\mathrm{N}_{1}=\mu_{0}\left[\left(1-\mathrm{p}_{11.3}-\mathrm{p}_{14}\right)\left(1-\mathrm{p}_{22.9}-\mathrm{p}_{210}\right)+\left(\mathrm{p}_{12.6}+\mathrm{p}_{15}\right)\right.$

$\mathrm{N}_{2}=\left(\mu_{1}+\mu_{11} \mathrm{p}_{14}+\mu_{12} \mathrm{p}_{15}\right)\left(\mathrm{p}_{01} \mathrm{P}_{20}+\mathrm{p}_{27}+\mathrm{p}_{28}\right)$

$\mathrm{N}_{3}=\left(\mu_{2}+\mu_{13} \mathrm{p}_{28}+\mu_{14} \mathrm{p}_{210}\right)\left(\mathrm{p}_{02} \mathrm{p}_{10}+\mathrm{p}_{15}+\mathrm{p}_{16}\right)$

$\mathrm{N}_{4}=\left(\mathrm{p}_{12.6}+\mathrm{p}_{15}\right) \mathrm{p}_{20}+\mathrm{p}_{10}\left(1-\mathrm{p}_{22.9}-\mathrm{p}_{210}\right)$

$\mathrm{N}_{5}=1-\mathrm{p}_{11.3}-\mathrm{p}_{14}-\mathrm{p}_{01} \mathrm{p}_{10}$

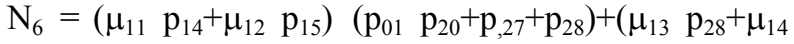
$\left.\mathrm{p}_{2,10}\right)\left(\mathrm{p}_{02} \mathrm{p}_{10}+\mathrm{p}_{12.6}+\mathrm{p}_{15}\right)$

Profit analysis:

Expected profit $=\mathrm{C}_{0} \mathrm{~A}_{0}-\mathrm{C}_{1} \mathrm{~B}_{0}-\mathrm{C}_{2} \mathrm{BR}_{0}-\mathrm{C}_{3} \mathrm{~V}_{0}-\mathrm{C}_{4} \mathrm{R}_{0}-\mathrm{C}_{5} \mathrm{AP}_{0}$ $\mathrm{C}_{0}=$ Revenue per unit up time

$\mathrm{C}_{1}=$ Cost per visit of repairman

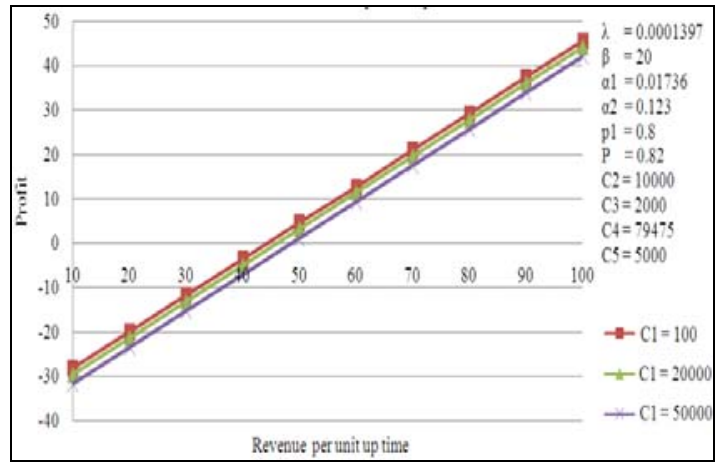

Fig. 2: Profit vs revenue per unit up time

$\mathrm{C}_{2}=$ Cost per unit time up time for which the repairman is busy for repair

$\mathrm{C}_{3}=$ Cost per unit up time for which the repairman is busy for replacement

$\mathrm{C}_{4}=$ Cost per unit replacement

$\mathrm{C}_{5}=$ Cost per unit time the line remains connected with the other system

Behavior of MTSF and the profit have been observed with respect to various rates/probabilities/costs also plotting graphs, though not shown here, It has been noticed that the MTSF and the profit get increased with increase in the values of repair rate, probability $\left(\mathrm{p}_{1}\right)$ but get decreased with increase the values of failure rate and costs of engaging repairman.

\section{CONCLUSION}

From the study made, it can be concluded that cutoff points for various rates/probabilities/revenue per unit up time/costs can be obtained which help decide that the user of the system that for the system to be profitable:

- What should be the lower limit of repair rate, revenue per unit up time, probability $\left(\mathrm{p}_{1}\right)$. What should be the upper limit of the failure rate, cost for engaging the repairman, From the cut-off point of the revenue per unit up time, the cost price of the product to be produced by the user can be fixed to get at least this revenue

\section{REFERENCES}

Gopalan, M.N. and H.E. Nagarwall, 1985. Cost-benefit analysis of a one-server two-unit cold standby system with repair and preventive maintenance. Micro Elect. Reliabil., 25: 267-269. DOI: 10.1016/0026-2714(85)90011-3 
Goyal, A., G. Taneja and D.V. Singh, 2009. Reliability and profit evaluation of a 2-unit cold standby system working in a sugar mill with operating and rest periods. Caledonian J. Eng., 5: 1-5.

Khaled, M.E.S. and S.E.S. Mohammed, 2005. Profit analysis of a two unit cold standby system with preventive maintenance and random change in units. J. Math. Stat., 1: 71-77. DOI: 10.3844/jmssp.2005.71.77

Parasher, B. and G. Taneja, 2007. Reliability and profit evaluation of a PLC hot standby system based on a master-slave concept and two types of repair facilities. IEEE Trans. Reliabil., 56: 534-539. DOI: 10.1109/TR.2007.903151

Taneja, G., D.V. Singh and A. Minocha, 2007. Profit evaluation of 2-out-of-3 unit system for an ash handling plant wherein situation of system failure did not arise. J. Inform. Optimiz. Sci., 28: 195-204.
Tuteja, R.K. and G. Taneja, 1992. Cost-benefit analysis of a two-server, two-unit, warm standby system with different types of failure. Micro Elect. Reliabil., 32: 1353-1359. DOI: 10.1016/00262714(92)90002-3

Tuteja, R.K., G. Taneja and U. Vashishtha, 2001a. Cost benefit analysis of a system where operation and Sometimes repair of main unit depends on subunit. Pure Applied Math. Sci., 53: 41-61.

Tuteja, R.K., G. Taneja and U. Vashishtha, 2001b. Analysis of a two dissimilar units system wherein standby Unit in working state may stop even without failure. Int. J. Manage. Syst., 17: 77-100. 